\title{
A RARE CASE OF OLFACTORY GROOVE SCHWANNOMA
}

\author{
Eberval Gadelha Figueiredo', Marcos Q.T. Gomes', Youji Soga ${ }^{3}$, \\ Robson L.O. Amorim ${ }^{4}$, Sérgio Rosemberg ${ }^{5}$, Manoel Jacobsen Teixeira ${ }^{6}$
}

Schwannomas are benign, slowly growing nerve sheath tumor $^{1-3}$. They account for about $8 \%$ of all intracranial tumors and can arise from any nerve containing Schwann cells $^{1-5}$. The most common location is the vestibular portion of the VIIIt ${ }^{\text {th }}$ cranial nerve and, less commonly, the $\mathrm{V}^{\text {th }}$, $\mathrm{IX}^{\text {th }}, \mathrm{X}^{\text {th }}$, and $\mathrm{VII}^{\text {th }}$ cranial nerves ${ }^{1,2,4,-10}$. The occurrence of a schwannoma not related to cranial nerves is exceedingly rare, the most common location being the anterior cranial fossa. Thus far, only twenty-nine cases have been described. They have been described under different designations, such as subfrontal, olfactory and olfactory groove schwannomas ${ }^{1-7,9,10}$ reflecting their enigmatic origin.

We describe a case of an anterior fossa schwannoma and discuss its pathogenesis.

\section{CASE}

A 49 years old-male had been complained of headache and loss of olfactory function since six months ago. Neurological examination revealed bilateral anosmia and optic atrophy with no further abnormalities. CT scan displayed a solid-cystic lesion based on the olfactory groove that heterogeneously enhances after contrast injection. MRI revealed an extra-axial T1 weighted isointense and $\mathrm{T} 2$ weighted hyperintense lesion and moderate amount of circumjacent edema (Fig 1). Preoperative diagnosis was an olfactory groove meningioma.

At surgery, the lesion was firm and moderately vascular. A pial plane was individualized and lesion was completely separate from the adjacent cortex. Both olfactory tracts were involved by tumor and adherent to skull base dura. Erosion of the ethmoid bone was noted after complete tumor removal. The floor of anterior fossa was reconstructed, frontal sinus mucosa was exenterated and pediculate aponeurosis was used to seal the anterior cranial fossa.

Postoperatively, patient presented cerebrospinal leakage and subsequent meningitis treated with antibiotics and cerebrospinal fluid lumbar drainage. He was discharged with no additional neurological morbidity. Histological exam disclosed spindle cells with elongated nuclei and fibrilary cytoplasm and a poorly cellu-
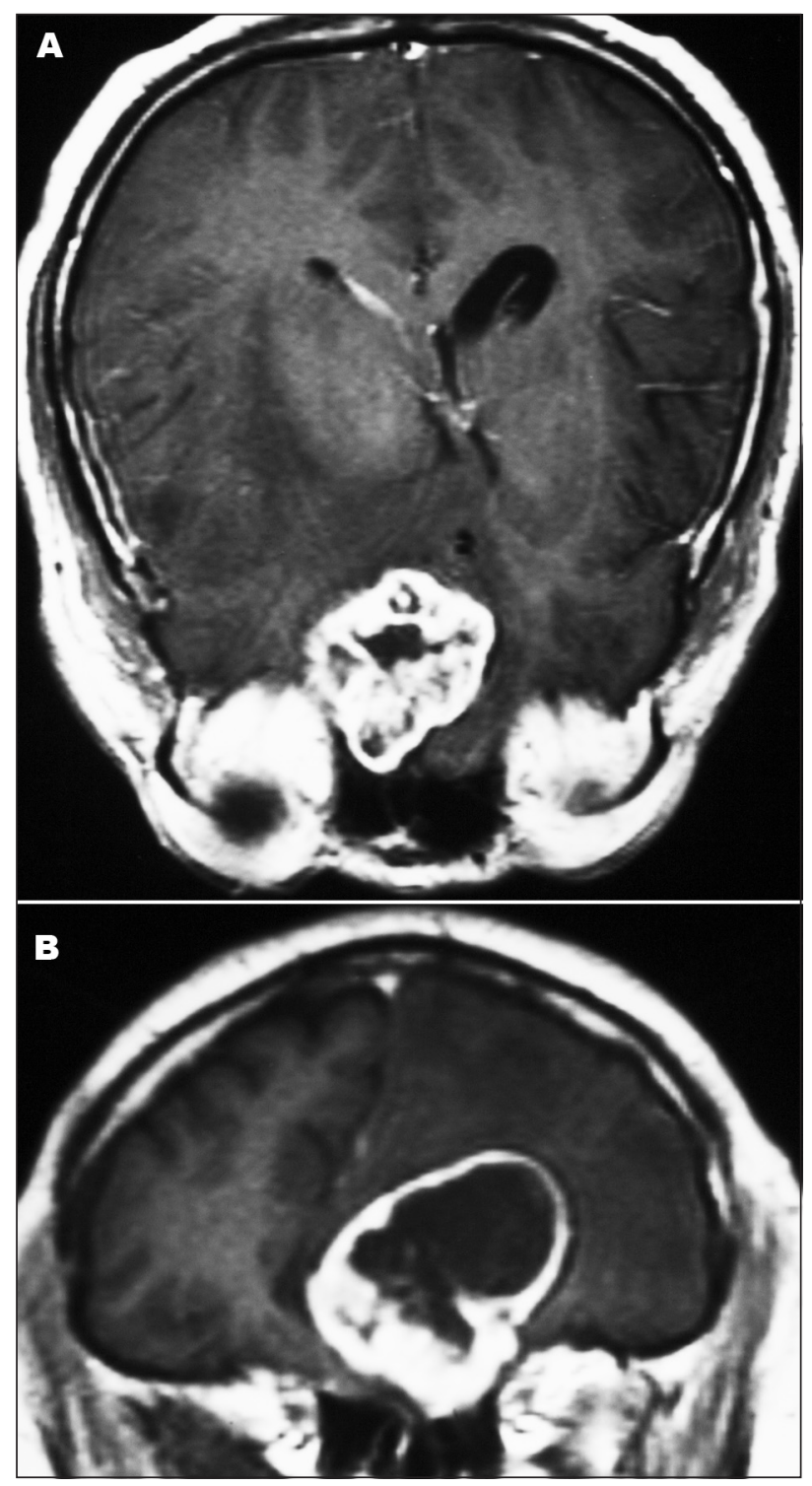

Fig 1. Magnetic resonance images depicting a solid-cystic extraaxial lesion presenting heterogeneous enhancement after gadolinium injection. Associated edema may be appreciated. [A] Axial view; $[B]$ Coronal view.

\section{UM CASO RARO DE SCHWANNOMA DA GOTEIRA OLFATÓRIA}

'Supervisor and Cerebrovascular Surgical Coordinator, Division of Neurological Surgery, University of São Paulo, School of Medicine, São Paulo SP, Brazil; ${ }^{2}$ Skull Base Surgical Coordinator, Division of Neurological Surgery, University of São Paulo, School of Medicine, São Paulo SP, Brazil; ${ }^{3}$ Assistant Professor, Department of Neurosurgery, Brain Research Institute, Nigata University, Nigata, Japan; ${ }^{4}$ Resident, Division of Neurological Surgery, University of São Paulo, School of Medicine, São Paulo SP, Brazil; ${ }^{5}$ Chairman, Department of Pathology, University of São Paulo, School of Medicine, São Paulo SP, Brazil; ${ }^{6}$ Chairman, Division of Neurological Surgery, University of São Paulo, School of Medicine, São Paulo SP, Brazil.

Received 30 October 2008, received in final form 2 January 2009. Accepted 17 April 2009.

Dr. Eberval G. Figueiredo - Rua Oscar Freire 1456/34 - 05409-010 São Paulo SP - Brasil. E-mail: ebgadelha@yahoo.com 


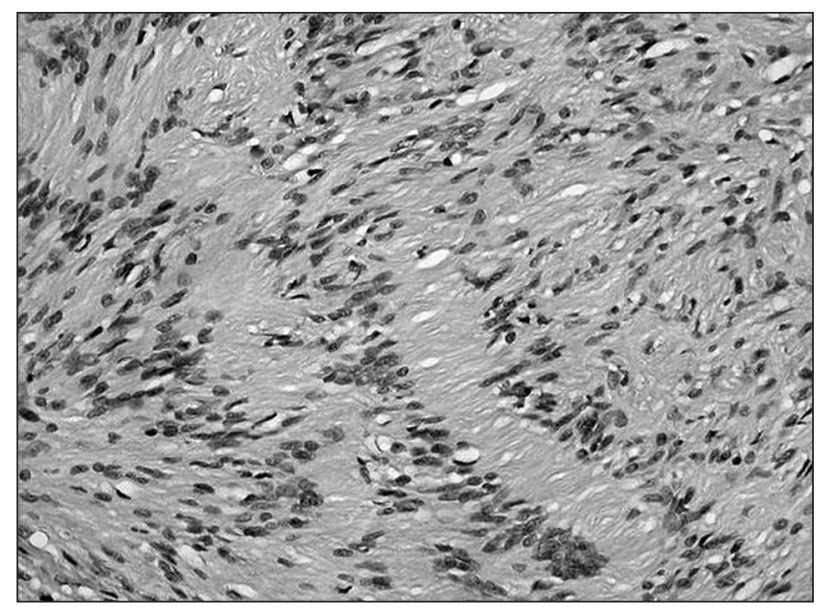

Fig 2. Histological exam depicts typical schwannoma features revealing spindle cells with elongated nuclei and fibrilary cytoplasm. A poorly cellular part consisting of an unstructured meshwork of loosely disposed cells is evidenced.

lar part consisting of an unstructured meshwork of loosely disposed cells (Fig 2). Immunohistochemical staining was negative for epithelial membrane antigen and positive for S-100 protein confirming the diagnosis of schwannoma. Patient and relatives have given their permission for publishing this case.

\section{DISCUSSION}

The occurrence of a schwannoma not related to cranial nerves is exceedingly rare, the most common location being the anterior cranial fossa. They occur more frequently in the anterior cranial fossa, mainly in the midline. The different terminologies associated with their rarity and enigmatic origin further complicates their study ${ }^{1-3,6-8}$.

Schwannomas mainly arise from nerve sheaths of peripheral and cranial nerves (exception for first and second cranial nerves). However, the pathogenesis of intracranial schwannomas not directed associated with cranial nerves has been puzzling ${ }^{1-8}$. Additionally, considerable debate exists whether they are primarily intra or extra-axial lesion ${ }^{1,2}$. There are several hypotheses concerning their probable origin. Developmental theories advocate these lesions primarily arise from aberrant Schwann cells in the central nervous system ${ }^{1-8,10}$. Other theories suggest origin from multipotential mesenchymal cells or displacement of neural crest cells forming focus of Schwann cells within brain parenchyma (schwannosis)'.

The subtype of schwannomas located in the base of frontal lobe and intimately related to the olfactory groove seems to be extra-axial rather than intra-axial lesions ${ }^{1,2}$. Even though, some authors have proposed a developmental origin for explaining their occurrence ${ }^{1}$, these lesions present several features that point the pathogenesis in other direction.

Neural structures in the olfactory groove and cribi- form plate include olfactory nerve and bulb, fila olfactoria, branches of trigeminal nerve, anterior ethmoidal nerves and nerve plexus of dural vessels. Hence, they represent the probable origin of this subset of schwannomas. It has been postulated that olfactory schwannomas originate from the olfactory bulb and nerve ${ }^{1,2,6}$. However, the olfactory bulbs and tracts lack Schwann cells, and hence can not give rise to the tumor. Schwann cells are normally present within the perivascular nerve plexuses around large arteries in the subarachnoid space and in adrenergic nerve fibers of cerebral arteries'. In addition, Schwann cells are found in nerves, such as meningeal branches of trigeminal nerves and anterior ethmoidal nerves, innervating the anterior fossa and olfactory groove'.

A most convincing evidence for an extraparenchymal origin is the existence of an intact pia-mater. Data concerning this finding have been lacking in the previously described cases. Considering these findings, meningeal branches of trigeminal nerve and anterior ethmoidal nerves are the most probable origin of these tumors.

In conclusion, anterior cranial fossa schwannomas are very rare tumors with 30 cases described so far. Their rarity may partially reflect that they have been overlooked, underreported or misdiagnosed. The most probable origin is anterior ethmoidal nerves or the meningeal branches of trigeminal nerve.

\section{REFERENCES}

1. Adachi K, Yoshida K, Miwa T, Ikeda E, Kawase T. Olfactory schwannoma. Acta Neurochir (Wien) 2007;149:605-610.

2. Ahmad FU, Gupta A, Sharma MC, Shukla G, Mehta VS. The enigmatic origin of subfrontal schwannomas: report of a case without hyposmia. Acta Neurochir (Wien) 2006;48:671-672.

3. Amador AR, Santonja C, Del Pozo JM, Ortiz L. Olfactory schwannoma. Eur Radiol 2002;12:742-744.

4. Bando K, Obayashi M, Tsuneharu F. A case of subfrontal schwannoma. No Shinkei Geka 1992;20:1189-1194.

5. Boyd JH, Dalsaso TA Jr, Bee CS, Smith KR Jr, Martin DS. Subfrontal schwannoma with intracranial mucocele: a case report. Am J Otolaryngol 1997;18:72-75.

6. Carron JD, Singh RV, Karakla DW, Silverberg M. Solitary schwannoma of the olfactory groove: case report and review of the literature. Skull Base 2002;12:163-166.

7. Souza HL, Ramos AM, Ramos CC, et al. Olfactory groove schwannoma: case report. Arq Neuropsiquiatr 2003;61:125-128.

8. Feigin I, Ogata J. Schwann cells and peripheral myelin within human central nervous tissues: the mesenchymal character of Schwann cells. J Neuropathol Exp Neurol 1971;30:603-612.

9. Gelabert M, Fernandez J, Lopez E. Schwannoma of the olfactory groove. Neurologia 2000;15:404-405.

10. Harada T, Kawauchi M, Watanabe M, Kyoshima K, Kobayashi S. Subfrontal schwannoma--case report. Neurol Med Chir (Tokyo) 1992;32:957-960. 